\title{
The Exploitation and the Development Perspectives of New Environmental Foliage Fiber
}

\author{
Guangxiao Wang \\ Tianjin Polytechnic University \\ NO.63 Cheng Lin Zhuang Road, Tianjin 300160, China \\ E-mail:wgx19820526@126.com \\ Yi Zhang \\ Tianjin Polytechnic University \\ NO.63 Cheng Lin Zhuang Road, Tianjin 300160, China \\ E-mail: tianjinzhangyi@126.com
}

\begin{abstract}
In this paper, the author reviewed the development of the natural fabrics, expounding the actuality of the exploitation on new type environmental natural fabrics, analyzing the production and the traits of the natural fabrics and the chemical fiber, and pointed out the significance of empoldering new environmental foliage fibers to meet the demand of textile machining. The author introduced several kinds of new environmental foliage fibers, and discussed making good use of the natural sources and the trash from the agriculture has been an obvious characteristic of developing green fiber and eco-textile in this paper as while. This paper further analyzes the development and market potential of the new environmental foliage fiber.
\end{abstract}

Keywords: Foliage fiber, Green fiber, Ecological textiles, Environmental protection

With increasing of people's living standards and the concept of consumption, the development of fibers and fabrics focusing on green and environmental protection for apparel will be based on natural fabrics. The orientation of aesthetic value of apparel returns to innocence, and tends to natural comfort, health, environmental protection and fashion. Since the 21 st century, the "green" consumption of the world has risen rapidly, and green fiber and eco-textiles has become the developing trend of the textile industry. It is an increase in the synthetic high-performance, high function and the natural degradation of the study, at the same time people pay more attention to the development and application of new environmental plant fiber. The new environmental plant fiber has broad space for development and market potential.

\section{Course of development of natural fiber}

Natural fiber as an important textile material has been dominant from the human civilization. On October 27, 1938, the first synthetic fiber nylon was born in the world. In the middle of 20st century, the synthetic fiber was produced in the large-scale rapidly all over the world, and its production has risen dramatically. From the early 1990s up to now, amount of the synthetic fiber is more than natural synthetic fibers, becoming the main fiber raw materials used in textiles and clothing. At the same time, to make synthetic fibers possess function like natural fibers will develop to the researchers' starting point.

On the one hand, we ceaselessly changes the property of synthetic fibers and add their new features to make up the consumers' advanced psychological needs after their material needs were met; on the other hand, we would solve the embarrassing questions that the synthetic fiber couldn't naturally degraded nothing but strengthen development of new natural fiber. Therefore, we should save the non-renewable energy, at the same time we must adequately employ the existing natural resources, synthetically make use of the agricultural wastes, and accelerate the study of the renewable and green plants fiber. From the end of the 20st century to present, development of the new environmental natural fibers of our country shows an unprecedented developing vision.

Natural fiber is divided into plant fiber (cellulosed fiber), animal fiber (protein fiber) and mineral fiber. Plant fiber is one of most abundant natural polymer materials in nature. According to statistics, an annual resources existing in the form of cellulose totally reach 100 billion tons in nature, far exceeding the total of oil reserves in the earth. A large number of natural cellulose resources are not being used effectively in the biological cycle. According to statistics, the total of global fiber breakthrough 70 million tons in 2005, of which natural fibers achieve 32,200,000 tons (exception of 
cotton, wool, silk in the natural fiber with 5.7 million tons), getting a 4.8 percent growth compared to 2004 .

We can see the results of "Tenth Five-Year Plan" and planning objectives of "Eleventh Five-Year" from Table 1. With a steady growth of the national economy, per capita Chinese fiber consumption reach 16kg by 2010, the proportion of industrial textiles will continue to growth. The proportion of natural fiber and chemical fiber decreased in 2000 compared to that in 2005 from table 1. Because the range of rise of global synthetic fiber is much larger than which of natural fiber, the range of rise of global synthetic fiber was 6.1 percent, while natural fiber 2.2 percent. We also can see that the total of global natural fiber increase in the form of wave since 1980 from table 2. Due to the impact of oil prices, the average price of chemical fiber steadily increased. In addition, the production of global cotton declined both in 2005 and 2006. But the quantity demanded of cotton continuously increased, and only the short fall of Chinese cotton was nearly three million tons. Under such circumstances, expediting the development and application of Chinese new environmental plant fibers is impending.

\section{The research several new environmental foliage fibers}

With deeply developing the raw materials of textile industry and continuously improving science and technology, on the one hand, we can develop new environmental foliage fibers from exploring in nature; on the one hand, we can develop new environmental foliage fibers from recycling the agricultural waste. In this way, not only we can synthetically make use of the resources and improve the environment, but also farmers' real income can increase. At present, we have successfully developed natural colored cotton, bamboo fiber, apocynum fiber, pineapple leaf fiber, banana fiber, cotton stalk skin fiber, coconut fibers, "alpinia speciosa" fiber and mulberry fiber. This paper briefly introduces these new environmental foliage fibers in the following.

\subsection{Natural Color Cotton}

Natural color cotton is a kind of non-white cotton produced by biological genetic engineering. At present there are several kinds of color cottons, such as brown, green, purple, gray, orange and so on. These color cottons have property of natural color, lasting color, and texture soft. It fits health and environmental protection standards from cultivation to production and from processing to consumer products. China begun to plant color cotton in 1987, which is more $2 \mathrm{O}$ years later than abroad, but it developed at an alarming rate. At present there are 15 provinces, municipalities and autonomous regions in china carrying out planting, researching and producing, and the total area of color cotton is more than 26.4 million acre. After the United States china has become the second largest country of planting color cotton in the world. In recent years, the United States, Japan, India, Egypt and other countries expedited the research and development work of color cotton.

Natural color cotton in China is mostly medium cotton and less long-staple cotton. The cellulose content of natural color cotton fiber is only 85 to 90 percent and the rest is mainly wax composition. The production of color cotton is low and its relative quality is poor. Color cotton has defects in aspect of fiber fineness, strength and length, and its physical and mechanical properties are worse than that of the white cotton. We generally blend it with white cotton, synthetic fiber to spin to improve the quality of yarn, and we usually have three blend ratio, such as 75/25, 40/60 and 10/90.

Color cotton widely was used to produce underwear, women, infant and child clothing, shirts, T-shirts, casual wear, towels and bedding and other fields. In addition, because color cotton with high added value brought about a very substantial profit, it has become one of "green" potential natural fibers of 21 st century.

\subsection{Apocynum}

Apocynum is a perennial herbaceous plant; it hosted in the saline lands, the sandy wastelands and the flood areas of Lop Nur. Apocynum has the common characteristics of moisture absorption, air permeability and higher strength with flax fiber. In addition, the fiber of apocynum is slender and soft, and its silk is smooth. Apocynum also has the antibacterial functions of health care, and it has obvious efficacy for hypertension and hyperlipidemia patients.

Apocynum fiber is a kind of bast fiber locating in the phloem tissue of stem, and its cellulose content is 54.8 to 58 percent. The cross section of apocynum fiber shows round or ellipse, and its vertical surface has vertical stria and bamboo cane. The length of apocynum fiber is 15 to 70 millimeter, the fineness of which is from 12 to 17 micron, the fracture strength is 7.4 centi-newton per dtex, and the elongation is 3.4 percent. The length of fiber is uneven, its amplexation strength is small, its elongation is low and its surface is smooth without curling. So we often spin by blending it with cotton, wool, silk and chemical fiber, such as the high-grade fabric of apocynum blended with cotton and tencel in market.

\subsection{Bamboo fiber}

Bamboo fiber is a green environment-friendly fiber materials successfully researched and designed by our country. Bamboo fabric was honored as "health materials most having development prospects in 21 st century" relying on Chinese abundant bamboo resources and the function of hygroscopicity, drape, dye ability, "breathe" ability, anti-bacterial deodorizing and anti-ultraviolet by natural. 
Bamboo fiber is divided into regenerative bamboo fiber and primary bamboo fiber. Regenerative bamboo fiber belongs to regenerative cellulose fiber, but primary bamboo fiber and the native is extracted directly from the bamboo fiber, which belongs to 100 percent natural plant fiber. The whole production process of bamboo fiber accords the green production standards, so it is a really green and environmental protection fiber in nature. However, the rigid of bamboo fiber is too large. So its spinning ability is not high. In addition, its contradiction between the linear density and length has also affected the fiber's quality and spinning performance in the production process.

The main components of bamboo fiber are cellulose, and also include hemicelluloses, lignin and a small amount of ash. Its cross section shows oval or waist round; it forms height "hollow" because of a lot of large and small gap in the fiber; its longitudinal surface has cross cane and a large number of micro-grooves; its distribution of fineness is uneven. Studies have shown that this special morphological structure of bamboo fiber will increase rapidly specific surface area and strengthen the wicking role of the capillary of fiber; moisture absorption and desorption improve; permeability of bamboo fiber is best in all types of fibers. In addition to, the bamboo fiber containing a variety of amino acid composition, and has the functions of good natural anti-bacterial, health care, anti-mildew, moth and anti-ultraviolet. And it is also a new type of natural plant fibers with vast potential of development. At present, the bamboo fibers are mainly used in the production of underwear, T-shirt, shirt, high-grade fashion, masks, bath towel, bathrobe, towels and bed clothes and other fields.

\subsection{Cotton Stalk skin Fiber}

Cotton stalk skin fiber, also known as cotton skin fiber or cotton stalk fiber, is a type of stem fiber belonging to seed plant. The resources of Chinese cotton stalks are rich, but generally they are only made paper or used as fuel use. The development of Chinese cotton stalk skin fiber is still at the starting stages. According to relevant information, the phloem cellulose content of external stem is up to 70 percent. Cotton stalk skin fiber inherits the basic performance of cotton, and even is better than cotton in some respects. Its average length is 34.38 millimeter, its length unevenness is 40.65 percent, its average strength 2.83 centi-Newton per dtex, and its average elongation reaches 11.12 percent.

\subsection{Pineapple leaf fiber}

Pineapple leaf fiber is an evergreen perennial herb, and it is extracted from pineapple leaves. At present, India and Japan and other countries carried out more systemic research and development of the pineapple leaf fiber extraction, try spinning and weaving and making clothes. In 1990s, Chinese scientific research institutions carried out the relevant research of the materialization properties of pineapple leaf fiber, Degumming and spinning yarns, and successfully produced the fabrics of pineapple leaf fiber and cotton, chemical fiber blended spinning.

The surface pineapple leaf fiber is rougher, its longitudinal surface has gaps and holes, its transverse surface has nodes, and cross section shows ovoid or polygonal and has middle cavity. The length of Single-fiber is 7 to 8 millimeters, it width is 7 to 18 microns, its broken strength is 3.06 centi-Newtons per dtex, its elongation is 3.4 percent, and the density of fiber is 1.543 grams per cubic meters.

At present, pineapple leaf fiber can spin yarns of 19.4 to 7.3 tex, or produce the yarns of 53, 27.8, and 19.4 tex blended with cotton. And also it can spin by blending yarns of 36 and 25 tex with flax. The fabrics of pineapple leaf fiber are easy to print and dye, sweat-absorbent and breathable, hard and not wrinkling, and it has good antibacterial and deodorization performances. It fits to high grade suits, shirts, divided skirt, bed clothes and decorative fabrics and so on.

\subsection{Mulberry fiber}

Mulberry fiber is a pure natural plant fiber by the mean of modern biotechnology separation and extraction. It has the characteristics of solid, flexible, moderate density and plasticity. The fabrics of mulberry fiber have the function of breathable moisture absorption and strong dye ability, and also have health function of skin care, nourishing hair, and lowering blood pressure. So mulberry fiber also is a new health-care textile material. The development and utilization of mulberry fiber also is the development of the recycling process of agricultural wastes. Mulberry fiber can develop more high value-added new products when it spins blended or interwoven with cotton, hemp, silk, chemical fiber and other fiber, and it has broad market prospects and ecological benefits.

The development and application of Chinese mulberry fiber remains advanced level in the world. The domestic research institutions have systematically researched morphology, crystal structure, thermal properties of mulberry fiber and fiber production process, and developed a series product, such as T-shirt, underwear, sleepwear, scarves and so on. More and more attention is paid to these products by the domestic and foreign traveling trader. It indicated that China has possessed the independent intellectual property rights of the whole process from peeling mulberry fiber and mechanized production to merchandise, and is also a completely new breakthrough in the field of the development of Chinese new natural plant fibers.

\subsection{Banana fiber}

Banana fiber, also known as the banana stem fiber or banana leaf fiber, is a new type of natural plant fibers. The major 
components of cellulose content of banana fiber is up to 60 to 65 percents, its single-fiber length is 80 to 200 millimeters, its elongation is 3 percents, and its mechanical physical properties are similar to flax. Banana fiber has the property of more coarse and hard, high strength, small elongation and high initial modulus.

At present, there are two kinds of methods to make banana fiber. One is to extract the fiber using original manual method from the leaf sheath, and it is mainly used in coarse ropes, portable bags, carpets and so on; some countries have widely used the method, such as Philippines, Malaysia, Uganda and so on. Another is the industrial production of banana fiber, because the properties of fiber are similar to flax, so they carried out degumming treatment using the extraction of flax fiber methods for reference, and also used the methods of biological degumming and flash-explosion and so on. Japan, India and other countries have developed banana fibers, and have blended banana fiber with cotton in a certain proportions to spin coarse yarns of 83.3 to 48.6tex. Thus the jeans and tennis clothes designed by them have the characteristics of special luster, quick moisture absorption and release. And they further developed high-grade curtains, towels, bed sheets and so on.

\section{8 "Alpinia speciosa" fiber}

"Alpinia speciosa" belong to zingiber class perennial herb. It grows in the low elevation mountain areas of subtropical Southeast Asia, and is generally cultivated in Japan and Chinese Taiwan. Its height about between 1 and 3 meters, and its leaves is as long as 70 centimeters and has the function of insect bite control and anti-bacterial. "Alpinia speciosa" has been long used as mothproof agents, cosmetics and food packaging.

In recent years, Japanese manufacturers successfully developed fork "alpinia speciosa" fiber using new technologies after developing kenaf fiber, bamboo fiber and banana fiber. It is a new type of antibacterial natural fibers. It is made into fabrics which have the properties of good mode-holding, bright color and cool comfort. At present, they have developed "alpinia speciosa" fiber and cotton blended spinning yarn of 83.3 to 19.4 tex, and the content of "alpinia speciosa" fiber is 5 to 30 percent.

\subsection{Coconut fiber}

Coconut fiber is a natural plant fiber extracted from the fruits of coconut palm. It mainly grows in Asian India and Sri Lanka, and the output of coconut fiber of the two countries respectively accounted for 75 and 22 percent all over the world. Asia is famous coconut producing regions, but only a small part of the coconut palm fruits is used to the fiber production and the majority of which abandoned or used as fuel. Because of the limitations of the development extent and the products purpose, this material with the potential using value has been blindly wasted. Therefore, foreign research institution has relevantly researched the physical and mechanical properties of coconut fiber.

Coconut shell can be divided into four layers, and they can respectively extract the fibers of different physical properties. Coconut fiber is mainly used in the production of rugs, cushion mats, rope and filter cloth.

\section{Conclusion}

With the textile restructuring and an increase in investment in innovation, the scope of new foliage fibers are increasing each day. Whether colored cotton, bamboo fiber, venetum fiber and other natural plant fiber, or synthetic corn, soybeans and other regenerated cellulose fibers, all greatly enriched the extension and intension of textile fiber. In recent years, with the energy crisis and environmental increasingly serious degradation and the people's concept of environmental protection continually deepening, fully recycling the existing natural resources and increasing the comprehensive development of agricultural waste have become the imperative in the development of green fiber and eco-textiles.

\section{References}

Mu Yao. (1980). Study Textile Materials, Beijing: Chinese Textile Press.

Jie Liu, \&Shiyan Lu. (2003), Natural colored cotton textile research and development, Textile Technology of Sichuan, 18-19.

Xiuling Zhang. (2004), Venetum distribution and the development and utilization of, Chinese Wild Plant Resources, 28-29.

Yuqin Wan, Yunhua Cui, \& Jianyong Yu. (2004). Bamboo fiber development and technology applications, Textile Journal, 25, 12.

Jixian Gong, \&Li Qin. (2003). One species of new textile material, Textile Journal, 3, 59-62.

Chongwen Yu. (2000). Pineapple fiber spinning technology, Textile Journal, 2000, 21, 32-35.

Ailian Guo. (2005), Pineapple leaf fiber and its application, Textile Science \& Technology of Shandong, 6, 49-51.

Wenqiang Zhang. (2002), Discussion on the pineapple leaf fiber development and using, Tropical Agricultural Engineering, 1, 22.

P. K. Banerjee. (2002), Indian J Fiber \& Text. Res, 27 (2), 111-116. 
N. Arun. (2000). Study on Few Properties-Banana Fiber, MAN-MADE TEXTIIES IN INDIA, 2, 68 -72.

P Bhama Iyer et al. (1995). Banana Fibers: A Stud on Properties of some Varieties, The Indian Textile Journal, 1, $42-48$.

Table 1. The contribution of textile industry on the national economy and social development from 2000 to 2010

\begin{tabular}{llll}
\hline Project & In 2000 & In 2005 & In 2010 \\
\hline Per capita the consumption of fiber (kg) & 7.5 & 13 & 16 \\
The consumption of clothing(thousand million yuan) & 3375 & 6826 & \\
Natural fiber: Chemical fiber & $41: 59$ & $35: 65$ \\
Clothing: Home textiles: Industrial textiles & $68: 19: 13$ & $54: 33: 13$ & $50: 33: 17$ \\
\hline
\end{tabular}

Table 2. The statistics of global fiber production from 1980 to 2004 (unit: 10,000 tons)

\begin{tabular}{llllllll}
\hline Name & In 1980 & In 1995 & In 2000 & In 2001 & In 2002 & In 2003 & In 2004 \\
\hline Chemical fiber & 1477 & 2600 & 3130 & 3389 & 3360 & 3593 & 3792 \\
Natural fiber & 1570 & 2108 & 2140 & 2048 & 2211 & 2157 & 2310 \\
\hline
\end{tabular}

Source: the Statistics Center of Chinese National Textile Industry Council 